\title{
A IMPORTÂNCIA DA ARTICULAÇÃO ENTRE O ENSINO DE QUÍMICA AMBIENTAL E O ENFOQUE CTSA
}

\section{THE IMPORTANCE OF THE ARTICULATION BETWEEN THE TEACHING OF ENVIRONMENTAL CHEMISTRY AND THE CTSA APPROACH}

\author{
Endrigo C. M. Gois ${ }^{1}$; Carla S. J. Santos ${ }^{2}$; Maria L. S. da Silva ${ }^{3}$; André L. C. de Sales ${ }^{4}$
}

\section{INTRODUÇÃO}

O desenvolvimento da ciência e da tecnologia tem acarretado diversas transformações na sociedade contemporânea, refletindo em mudanças nos níveis econômicos, políticos, sociais e, sobretudo, ambientais. A perspectiva CTSA é uma abordagem didática que se iniciou desde a década de 1960 como mecanismo metodológico que permite compreender as interrelações e articulações entre Ciência, Tecnologia, Sociedade e Ambiente, que deu origem a uma vertente na qual se inclui as consequências decorrentes dessas interações com o meio ambiente, por isso, nesse sentido, é usualmente designada da seguinte maneira: abordagem Ciência-Tecnologia-Sociedade-Ambiente (CTSA).

A articulação entre o ensino de química ambiental e o enfoque CTSA faz-se pertinente e é justificável a partir do momento que os discentes constroem um pensamento complexo acerca da realidade que os circunda, bem como conseguem reestruturar a construção de conhecimentos científicos mediante uma perspectiva pedagógica de cunho interdisciplinar, baseando-se a partir do contexto em que eles estão inseridos, possibilitando a elaboração da criticidade e da reflexão no que se refere ao progresso científico-tecnológico já elaborado e desenvolvido pelo ser humano.

O objetivo desse trabalho consistiu em analisar qualitativamente as opiniões e suas implicações de um determinado grupo de graduandos do curso de licenciatura em química no tocante à importância da articulação entre o ensino de química ambiental e o enfoque CTSA dentro de uma abordagem educativa enquanto proposta metodológica que visa a formação social e cidadã enquanto sujeitos críticos, autônomos e reflexivos, sendo investigados nessa temática em questão.

\section{FUNDAMENTAÇÃO TEÓRICA}

A química ambiental consiste no "estudo das fontes, das reações, do transporte, dos efeitos e dos destinos de espécies químicas na hidrosfera, na atmosfera, na geosfera, e na

\footnotetext{
${ }^{1}$ Licenciatura em Química, IFPI, e.carllos35@gmail.com

${ }^{2}$ Licenciatura em Química, IFPI, carla sabrina15@ hotmail.com

${ }^{3}$ Licenciatura em Química, IFPI, lannalanninha2008@ hotmail.com

${ }^{4}$ Mestre, IFPI, and.csales@ifpi.edu.br
} 
antroposfera, além dos efeitos das atividades humanas nelas" (MANAHAN, 2013, p. 28).

De acordo com Santos e Maldaner (2011), os estudos CTSA no âmbito educacional surgiram associados ao ensino de Ciências. Dessa forma, o ensino de Ciências exige uma base de conteúdos articulada a questões relativas a aspectos científicos, tecnológicos, sociais, econômicos e políticos. Sendo assim, essa articulação fará com que os aprendizes se apropriem de ferramentas culturais para atuar de forma participativa no mundo em que estão inseridos.

Segundo Santos e Schnetzler (2010), essa abordagem possibilita a compreensão dos processos científicos e tecnológicos, compreendendo os efeitos da ciência e das tecnologias na sociedade. Além disso, foca-se na busca pela discussão da necessidade de mudança de atitude dos indivíduos para o uso mais consciente das tecnologias, estabelecendo uma visão de construção de um paradigma de desenvolvimento comprometido com preservação planetária.

Para Morin (2003), a compartimentalização dos saberes e a incapacidade de articulálos uns aos outros consistem nos problemas mais graves que necessitam ser reavaliados no âmbito do ensino. Portanto, o ensino que se propõe é aquele que permita e viabilize condições inerentes ao desenvolvimento de habilidades e competências, uma vez que as estratégias de ensino sejam bem estruturadas, organizadas, definidas e intencionais.

Nesse sentido, é necessário atuar de maneira alternativa em oposição ao modelo tradicional de ensino, reestruturando os conteúdos de química e suas diversas áreas afins em temas sociais e tecnológicos, visto que os conteúdos disciplinares podem e devem ser articulados à medida em que eles se tornam pertinentes e relevantes para a análise crítica e para a elaboração de propostas para a resolução dos problemas apresentados (REBELLO et. al., 2012 apud FIRME e AMARAL, 2011).

Isso significa que os conteúdos de ensino relacionados à química ambiental não se podem restringir à lógica fragmentária e descontextualizada das disciplinas científicas, valorizando exclusivamente o conhecimento de teorias e fatos científicos, pelo contrário, fazse pertinente reestruturá-los e reelaborá-los, articulando-os a temas sociais relevantes (JUNIOR; CORIO; FERNANDEZ, 2009).

Valendo-se dessa perspectiva dentro do contexto educacional, seu caráter interdisciplinar compreende uma área de estudo cuja preocupação maior é tratar a ciência e a tecnologia, tendo em foco suas relações, consequências e soluções. É interessante ressaltar a importância social dessas vertentes, enfatizando a imprescindível avaliação crítica e análises reflexivas acerca da relação científico-tecnológica e a sociedade (JUNIOR; CORIO; FERNANDEZ, 2009). 
O ensino de química, nas suas diversas vertentes, precisa propiciar novas propostas metodológicas que indiquem a constituição educacional e a ressignificação dessa ciência, e que compõe diferentes contextos dentro da educação científica, tecnológica e social (PINHEIRO et. al., 2013).

Fica evidente a necessidade de se articular o ensino de química ambiental junto ao enfoque CTSA, com o intuito relevante e propício de se viabilizar aos discentes a adquirirem conhecimentos científicos que os permitam agir e participar como cidadãos na sociedade, apresentando tanto um comportamento ativo quanto um posicionamento crítico, regidos pela tomada de decisão (MONTEIRO, 2016).

\section{METODOLOGIA}

Com relação aos procedimentos metodológicos, optou-se pela abordagem qualitativa. Segundo Minayo (2012), a pesquisa qualitativa responde a questões muito peculiares e particulares. Ela se concentra e se preocupa com um nível de realidade que não pode ser quantificado. Ou seja, ela trabalha com o universo dos significados, dos motivos, das aspirações, das crenças, dos valores e das atitudes. Como mecanismo de coleta de dados realizou-se a aplicação de questionário virtual contemplando 3 perguntas abertas e 1 pergunta fechada junto aos discentes pertencentes ao Instituto Federal de Educação, Ciência e Tecnologia do Piauí - IFPI, campus Teresina-Central. O contexto experimental foi a própria instituição de ensino anteriormente citada, na cidade de Teresina - PI, sendo a amostragem constituída por 20 discentes de graduação em licenciatura em química.

Elaborou-se um questionário virtual contemplando perguntas abertas e fechadas a fim de investigar a importância da articulação entre o ensino de química ambiental e o enfoque CTSA dentro de uma abordagem educativa enquanto proposta metodológica, tendo em vista as concepções, percepções e suas respectivas implicações, com o intuito de analisar e refletir criticamente acerca da visão e do posicionamento que se pôde inferir a partir de seus relatos. Após a elaboração do questionário virtual, o mesmo foi aplicado a um determinado grupo de licenciandos, conforme já supracitado anteriormente. Ao final, logo após resolução do questionário virtual, os dados obtidos foram registrados e analisados.

\section{RESULTADOS E DISCUSSÕES}

A partir do quadro 1 abaixo, constatou-se que a articulação entre o ensino de química ambiental e o enfoque CTSA é necessário e primordial dentro dos ambientes acadêmicos, uma vez que tal abordagem metodológica provoca o exercício da investigação, de modo a 
promover o desenvolvimento de habilidades, competências e saberes, bem como a formação cidadã mais crítica, reflexiva e consciente frente às consequências dos impactos ambientais proveniente do progresso intercalado da ciência e tecnologia (MONTEIRO, 2016; MORIN, 2003).

Constatou-se que essa perspectiva é de extrema importância no sentido de relacionar o conhecimento científico de maneira contextualizada, aproximando os conteúdos estudados à realidade vivida pelos próprios discentes, uma vez que eles evidenciaram suas percepções e concepções mais claramente frente a essas questões. Constatou-se que é de extrema relevância discutir a importância social da ciência e da tecnologia, tendo em vista a necessidade de promover debates e discussão que essas vertentes desempenham. Nesse sentido, o espaço da sala de aula se configura como mecanismo primordial e oportuno para se discutir e debater tais perspectivas articuladas coerentemente (JUNIOR; CORIO; FERNANDEZ, 2009).

Quadro 1: Resultados obtidos mediante aplicação de questionário enquanto mecanismo de análise avaliativa acerca das concepções, percepções e reflexões dos depoentes no tocante à temática proposta.

\begin{tabular}{|c|c|}
\hline PERGUNTAS & RESPOSTAS OBTIDAS \\
\hline $\begin{array}{l}\text { 1. Você considera importante a articulação } \\
\text { entre o ensino de Química Ambiental e o } \\
\text { enfoque CTSA dentro do contexto } \\
\text { educacional? Comente. }\end{array}$ & $\begin{array}{l}\text { "É a partir dessa articulação que se pode desenvolver } \\
\text { competências e habilidades, incorporando uma } \\
\text { perspectiva mais crítica e reflexiva no que diz respeito } \\
\text { ao avanço científico e tecnológico." } \\
\text { "Uma vez que a perspectiva CTSA aborda o ensino } \\
\text { científico de forma bem próxima da realidade do } \\
\text { estudante, isso pressupõe bons resultados no que diz } \\
\text { respeito ao ensino e aprendizagem." } \\
\text { "Sim, é importante para a formação de um bom } \\
\text { cidadão, na qual é o papel principal da educação." }\end{array}$ \\
\hline $\begin{array}{l}\text { 2. Você considera relevante discutir a } \\
\text { importância social da Ciência e da } \\
\text { Tecnologia, enfatizando a imprescindível } \\
\text { avaliação crítica e análises reflexivas acerca } \\
\text { da relação científico-tecnológico e a } \\
\text { sociedade no espeço dialógico da sala de } \\
\text { aula? Comente. }\end{array}$ & $\begin{array}{l}\text { "A ciência e a tecnologia são duas ferramentas úteis e } \\
\text { essenciais para o progresso da humanidade, e } \\
\text { discussões acerca desses assuntos precisam estar } \\
\text { presentes no contexto escolar." } \\
\text { "É necessário ter em mente o papel social da ciência e } \\
\text { da tecnologia, uma vez que o espaço da sala de aula é } \\
\text { oportuno e fundamental para se articulá-los } \\
\text { coerentemente." } \\
\text { "É necessário que se saiba posicionar-se criticamente } \\
\text { frente a esses avanços. A sala de aula é um ambiente } \\
\text { propício para o estudo dessas relaçôes." }\end{array}$ \\
\hline $\begin{array}{l}\text { 3. Na sua opinião, como o ensino de Química } \\
\text { Ambiental articulado ao enfoque CTSA } \\
\text { proporciona o desenvolvimento do } \\
\text { pensamento crítico-reflexivo frente às } \\
\text { consequências decorrentes do impacto } \\
\text { científico e tecnológico? Comente. }\end{array}$ & $\begin{array}{l}\text { "Essa articulação pode despertar um olhar mais } \\
\text { crítico e reflexivo para esse contexto, permitindo a } \\
\text { tomada de decisão consciente frente aos impactos } \\
\text { ambientais." } \\
\text { "Aliar os aspectos científicos, sociais e tecnológicos } \\
\text { ao ensino de Química Ambiental permite compreender } \\
\text { os impactos que repercutem na sociedade em geral e } \\
\text { se posicionar criticamente e atuante frente a esses }\end{array}$ \\
\hline
\end{tabular}




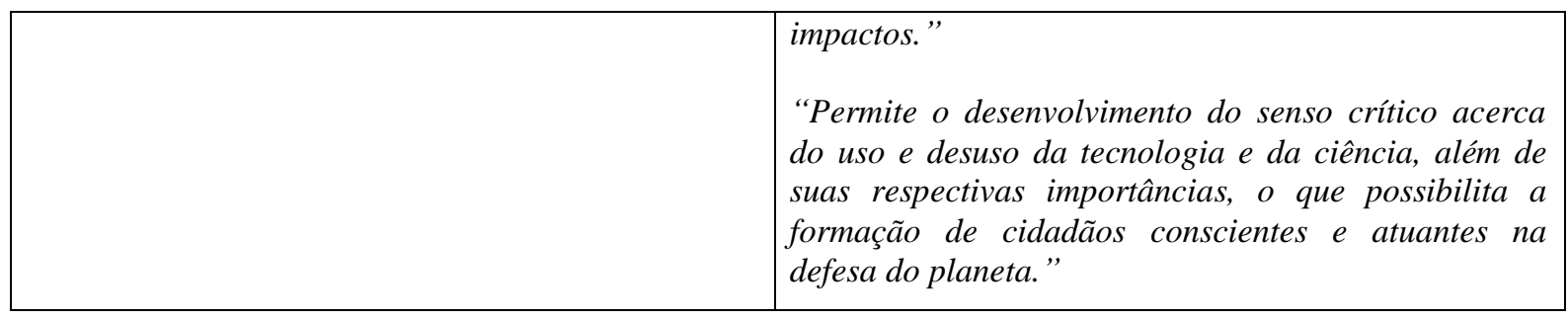

Fonte: Própria

Figura 1: Gráfico referente à quarta pergunta, gerado a partir da opinião dos discentes no tocante à articulação entre o ensino de Química Ambiental e o enfoque CTSA enquanto abordagem de caráter metodológico.

Opinião dos discentes no tocante à articulação entre o ensino de Química Ambiental e o enfoque CTSA enquanto abordagem de caráter metodológico.

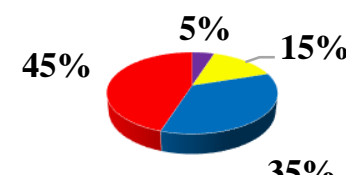

- Insuficiente = Regular - Bom - Ótimo

Fonte: Própria.

Com base na figura 1 , no que diz respeito à articulação entre o ensino de química ambiental e o enfoque CTSA enquanto mecanismo de caráter pedagógico e metodológico, constatou-se que 45\% consideram-na uma atividade ótima, 35\% consideram-na uma abordagem boa, $15 \%$ consideram-na uma proposta regular e 5\% consideram-na uma ferramenta insuficiente. É notório que a maioria concorda e considera essa perspectiva como ferramenta pedagógica no sentido de enriquecer substancialmente a si mesmos e o processo educativo, tendo em vista a sua importância e dinamismo dentro do contexto educacional. É válido destacar que as proposições dos discentes sobre essa temática são imprescindíveis e de extrema pertinência, levando em consideração suas percepções, posições, reflexões, pensamentos e atitudes, subsidiando enfoques humanísticos, de modo a perceber a educação ambiental dentro desse contexto maior como principal mecanismo de construção e formação de uma consciência mais científica, tecnológica, ambiental e sobretudo cidadã (SANTOS; SCHNETZLER, 2010).

\section{CONCLUSÕES}

Fica evidente a importância de se utilizar novas metodologias articuladas ao ensino de química ambiental, a saber o enfoque CTSA, visto que essa abordagem metodológica e pedagógica desempenha um imprescindível papel em sala de aula para o enriquecimento nas esferas científica, tecnológica e social dos discentes dentro do contexto educacional. Portanto, a articulação entre o ensino de química ambiental e o enfoque CTSA promove o desenvolvimento e o enriquecimento de suas teorias pessoais que lhes são inerentes acerca da 
ciência, tecnologia e da sociedade, além do conhecimento científico construído e adquirido ao longo de suas carreiras acadêmicas e formação social e cidadã.

\section{REFERÊNCIAS}

JUNIOR, L. P. C.; CORIO, P.; FERNANDEZ, C.; As Representações Sociais de Química Ambiental dos Alunos Iniciantes na Graduação em Química. Química Nova na Escola. Seção: O Auno em Foco, São Paulo, nº 1, vol. 31, p. 46 - 54, fevereiro, 2009.

MANAHAN, S. E. Química Ambiental. 9 ed. Porto Alegre: Bookman, 2013.

MINAYO, M. C. de S.; Análise qualitativa: teoria, passos e fidedignidade. Ciência \& Saúde Coletiva, vol.17, nº 3, p. 621 - 626, 2012.

MONTEIRO, E. D. de Novaes; Sequência didática com abordagem CTSA para o estudo das funções orgânicas. Dissertação de Mestrado em Ensino de Ciências. Niterói, Universidade Federal Fluminense, 2016.

MORIN, Edgar. A cabeça bem-feita: repensar a reforma, reformar o pensamento. $8^{\mathrm{a}}$ ed. Rio de Janeiro: Bertrand Brasil, 2003.

PINHEIRO, Nilcéia Aparecida Maciel; SILVEIRA, Rosemari Monteiro Castilho Foggiatto; BAZZO, Walter Antonio. Ciência, Tecnologia e Sociedade: A Relevância do Enfoque CTS para o Contexto do Ensino Médio. Ciência \& Educação, Paraná, v. 13, n. 1, p. 71 - 84, set./out. 2007.

PINHEIRO, Nilcéia Aparecida Maciel; SILVEIRA, Rosemari Monteiro Castilho Foggiatto; STIIRMER, Júlio César; STANGE, Simone Moraes. Refletindo acerca da Ciência, Tecnologia e Sociedade: Enfocando o Ensino Médio nos liames da Química. Signos, ano 34, nº 2, p. 11-27, Paraná, 2013.

REBELLO, G. A. F. et al.; Nanotecnologia, um tema para o ensino médio utilizando a abordagem CTSA. Química Nova na Escola. Seção: Química e Sociedade, São Paulo, nº 1 , vol. 34, p. 3-9, fevereiro, 2012.

SANTOS, Wildson Luiz Pereira dos; MALDANER, Otavio Aloisio. Ensino de Química em Foco. Ijuí: Ed. Unijuí, 2011.

SANTOS, Wildson Luiz Pereira dos; SCHNETZLER, Roseli Pacheco. Educação em Química: Compromisso com a cidadania. 4ª ed. Ijuí: Ed. Unijuí, 2010. 